\title{
Using numerical modelling to represent parameters affecting cave mining
}

\author{
K Suzuki Morales UNSW Sydney, Australia \\ FT Suorineni UNSW Sydney, Australia
}

\begin{abstract}
Caving geomechanics is still not well-understood, mainly because it is not possible to enter the cave and measure all the rock mass parameters involved in the caving process. Caving geomechanics is a typical example of rock mechanics being a data-limited problem. However, even if the problem cannot be completely physically described, it is critical to make stepwise advances towards its understanding. Numerical models have an advantage over empirical methods when it comes to understanding the physics of a rock mechanics problem such as caving geomechanics. In using numerical modelling, various hypotheses can be tested and compared to the actual behaviour of the rock mass response to caving. Predicting rock mass caveability remains a challenge. Available empirical tools aiming to predict caveability are known to be unreliable, while numerical modelling has the challenge of identifying and accounting for potential factors to be included in such models to make the outputs reliable. The complexity of these models and their sizes result in excessive run times. This paper presents the next step in numerical modelling in an attempt to understand caving mechanics as a basis for a better caveability prediction guide in the process of mine design in caving mines. The study is based on identifying the critical factors and their role in caving performance. These issues are investigated using a discrete element code where pre-existing discontinuities are explicitly incorporated.
\end{abstract}

Keywords: caveability prediction, empirical methods, numerical modelling, geomechanics

\section{Introduction}

The success of a caving operation is related to the geomechanical condition of the rock mass, particularly its caveability, which should be predicted based on the quantification of critical factors affecting it. Given that relevant data describing these factors is generally unavailable or cannot be easily obtained in the field, the rock mass behaviour has to be extrapolated from laboratory-scale tests. However, it cannot be expected that laboratory-scale samples will fail following the same failure mechanism as a rock mass that is under a more complicated stress path. The evaluation of the rock mass quality is limited because only a few properties are usually measured in the laboratory to characterise the rock mass. The intact rock strength, for example, is typically quantified by uniaxial compression tests that underestimate the compressive strength under high confining stresses. Another example is post-peak behaviour, which is usually not considered since it is hard to measure and requires more resources. Additionally, the rock mass behaviour is extrapolated even when there is no evidence to justify its response under given conditions.

Given the uncertainty in data, it should be attempted to gain understanding, instead of making absolute predictions (Starfield \& Cundall 1988). A better understanding of the rock mass behaviour can be gained by using numerical modelling instead of empirical methods, because numerical modelling can test various hypotheses that can be compared to documented cases. However, empirical methods will remain essential since numerical models need to be validated against empirical evidence. Numerical methods have the advantage in that they can represent complex geometries, material properties, failure mechanisms and boundary conditions. These features cannot be included in analytical methods, and empirical methods inherently include complexities in the rock mass behaviour but they cannot explain the physics. 
This paper first presents the current state-of-the-art of empirical tools and numerical modelling aiming to predict caveability. Second, critical factors affecting caveability are identified and their role on caveability proposed to be investigated using a discrete element code. The aim of this work is to define a basis for guidelines for developing a new tool for caveability prediction.

\section{Caveability prediction methods}

\subsection{Empirical methods}

Early empirical attempts to predict caveability were reported based on the acquired experience from mines in the United States of America, where caveability was related to fracture spacing and mineralisation (King 1945), and to rock quality designation (RQD) and the average quantity of secondary blasting (McMahon \& Kendrick 1969). In later years, the rock mass strength and the presence of weaker lithologies was identified to be more effective in predicting caveability (Obert et al. 1976). Further research suggested that not only the rock mass features were critical, but also that the undercut area was an indicator of the formation of a stable arch (Vera 1981). The most used methodologies in predicting caveability to date are Laubscher's caveability chart (1987) and the extended Mathews stability graph (Mawdesley 2002), which are based on rock mass classification systems and on a measure of the undercut geometry. However, they do not adequately include factors influencing caveability as their foundations rely on the Rock Mass Rating (RMR) System (Bieniawski 1973) and the Q-system (Barton et al. 1974), respectively. The most recent alternative proposed is the application of the rock engineering system (RES) methodology to predict caveability (Mohammad Khani 2016; Rafiee et al. 2015), which identifies critical parameters, but its calibration has not been correctly justified.

This section is based on the Laubscher's caveability chart and the extended Mathews stability graph, particularly on the applicability of their components to caveability prediction and their main limitations.

The Laubscher's caveability chart has been considered a reference in block caving mine design given the limited experience in cave mining when it was first proposed. This approach uses the Mining Rock Mass Rating (MRMR) to describe the rock mass quality (Laubscher \& Taylor 1976), which is a classification system that extends Bieniawski's RMR to represent caveability. Thus, MRMR was originally based on the same database used for the development of RMR. MRMR assigns a basic rating to the rock mass based on geological parameters and then applies engineering adjustments that should not reduce the basic rating by more than 50\% (Laubscher \& Jakubec 2001). MRMR to date is considered the best option to quantify the rock mass under caving conditions, but its limitations are not usually considered. The calibration of MRMR ratings and adjustments was based on the experience of the author, but no database has been published to justify any of the versions that can be found in the literature. Additionally, the stability boundaries plotted on the chart have been updated visually over time, but just as for MRMR, no published information justifies the location of the new boundaries (Lorig et al. 1995; Stewart \& Trueman 2001).

Six different versions of the Laubscher chart can be found in the literature and the main difference between them is the number of case histories and the position of stability boundaries. These versions can create confusion since cases evaluated using different guidelines cannot be compared. A large number of mines have used Laubscher's chart reporting either successful caving or significant differences between actual undercut sizes and empirical predictions (Figure 1(a)). Differences can be found in cases which cannot be correctly represented, mainly because of MRMR limitations such as rock masses characterised by the presence of major structures or adjacent mining. One critical example is the case of the stable arc formed at the El Salvador mine in Chile when the rock mass did not allow the propagation of caving for the estimated open area (De Nicola \& Fishwick 2000). Another catastrophic event was the air blast that occurred at the Northparkes mine in Australia, which was generated because caving never could be adequately initiated as induced stresses did not overcome the rock mass strength to fail (Ross \& van As 2005).

The most recent empirical alternative to replace Laubscher's chart is the extended Mathews stability graph. This graph considers the stability number $\mathrm{N}$ to quantify the rock mass quality, which re-evaluates the 
parameters in the Q-system to assess open stope stability and its potential failure mechanisms (Mathews et al. 1981). The Mathews stability graph was linked to caveability prediction when an update, aiming to include more data, estimated the position of Laubscher's caving boundaries on the Mathews stability graph (Stewart \& Forsyth 1995). Caving cases were subsequently incorporated in the extended Mathews stability graph by Mawdesley (2002). However, some limitations need to be considered as its original application was open stope mining. The extended Mathews stability graph contains 483 cases evaluated using the original version of the stability number $\mathrm{N}$ factors, from which only 15 successfully achieved caving of the 27 cases taken from block and panel caving mines (Figure 1(b)). More cases need to be incorporated to close the gap between open stoping and caving data (Mawdesley 2002). Moreover, the original stability number $\mathrm{N}$ is based only on 26 case histories and 29 case histories from literature (Potvin 1988), which is not enough to adequately define the stability number $\mathrm{N}$ factors and boundaries (Suorineni et al. 2001). Users of Figure 1 (b) are also cautioned that the definition of caving is different from what was in the original stability graph. In the original stability graph, caving means $30 \%$ of stope surface sloughing, while in Figure $1(b)$, caving implies caving as in block or panel caving.

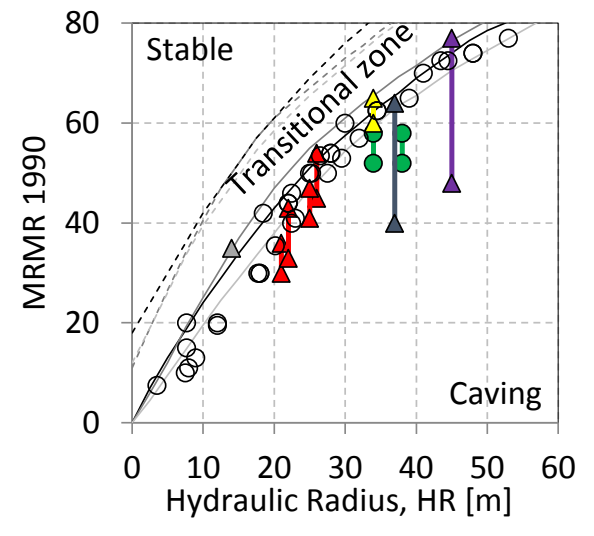

(a)

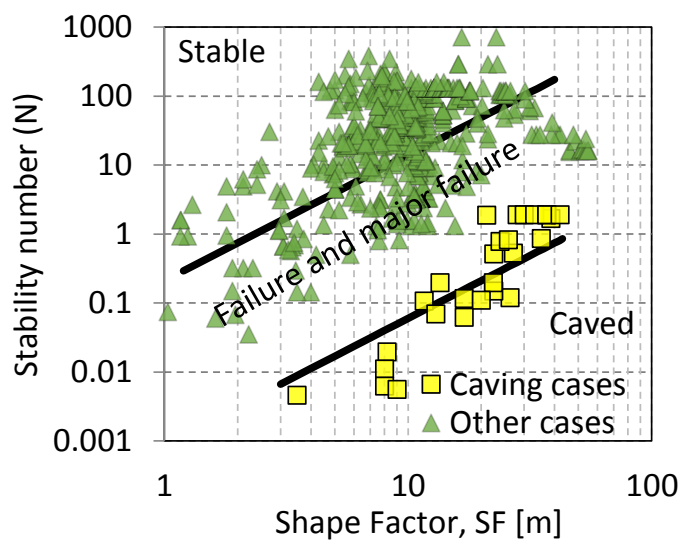

(b)

Figure 1 (a) Laubscher's caveability chart including case histories; and, (b) Extended Mathews stability graph grouping case histories as caving or non-caving cases (Suorineni et al. 2014)

In conclusion, both empirical charts inherit the limitations of the rock mass classification systems used to define the rock mass quality, the MRMR and the Q-system respectively, being further affected by the cases used to calibrate the ratings and adjustments in each case. RMR and $Q$ were not developed for predicting caveability; and therefore, they do not contain the critical factors influencing caveability, despite any adjustment factors.

\subsection{Numerical methods}

Another alternative to predict caveability is to assess the problem using numerical methods. The numerical assessment of rock mechanics problems and its applications have significantly improved over the last 40 years, mainly because of the development of continuum and discontinuum models, the capability to simulate fractures, the formulation of complex constitutive models, the development of successful software packages (Jing 2003), and to some extent, the availability of fast computers. However, they are still inadequate to represent the rock mass behaviour in specific applications, and the quality of their prediction is only as good as the limited information obtained from underground mapping and borehole surveys.

Numerical methods are implemented in a wide range of codes that use continuum and discontinuum techniques. Both options have advantages and limitations, but the choice of one of them over the others depends on the requirements and expected outcomes in the problem solution. Some of the disadvantages can be avoided by combining continuum and discrete models. However, these approaches are still limited to $2 \mathrm{D}$ because of the significant computational time required to run a mine-scale model (Elmo et al. 2012; Lisjak et al. 2012; Vyazmensky et al. 2007). 
Continuum techniques may consider simple geometries and should be used in systems with few fractures. This approach requires an appropriate homogenisation technique to identify the material parameters in order to represent the equivalent continuum, which is usually complex and valid only over a certain representative elementary volume (REV) (Jing 1998). The constitutive model used to represent the rock mass should consider the effect of the stresses acting on the joints to represent jointed rock masses (Cai \& Horii 1993). For instance, the representation of anisotropy is limited to ubiquitous joint constitutive models, since the relative displacement of blocks and their interlocking cannot be adequately accounted for (Elmo et al. 2012). Continuum models are also limited because they are sensitive to mesh size and to rock mass properties that are difficult to determine such as post-peak properties. The best approximation of a continuum model providing good results in large-scale caving back analysis is the Ubiquitous Joint Rock Mass (UJRM) model, which considers as input data results from the Synthetic Rock Mass (SRM) technique (Sainsbury 2012). However, it still needs to be validated with additional mining experience.

Discontinuum approaches are commonly referred to the discrete element method that treats the material as an assembly of blocks representing jointed rock masses where large-scale displacements are allowed. Based on the solution algorithm, the term distinct element method (DEM) refers to the explicit time domain solution of the original equations of motion (Cundall \& Strack 1979), while discontinuous deformation analysis (DDA) refers to an implicit formulation (Shi \& Goodman 1988). DEM represents the rock mass as an assemblage of interlocked elements bonded by contacts that are continuously identified and updated to solve the equations of motion of each block (Jing \& Hudson 2002). Typical 3D DEM codes are 3DEC (Itasca Consulting Group, Inc., 2016), which uses deformable or rigid polygonal-shaped blocks, and PFC3D (Itasca Consulting Group, Inc., 2014), which simplifies the problem by using rigid spherical particles. In PFC3D, the quality of the prediction is influenced by the particle size within the model since it restricts the scale of the physical phenomena and defines the material properties by artificially scaling them to the particle size. 3DEC differs from PFC3D in its ability to represent a zero initial porosity condition and in the highly interlocked irregular shapes that provide resistance after contact breakage as well as having the capacity to represent higher uniaxial compressive strength to tensile strength ratios and friction angles (Garza-Cruz \& Pierce 2016). These approaches can help in the understanding of caveability given the inherent discontinuous nature of the caving process (Brown 2002). However, they require a large number of small elements that need to move large distances; in other words, they require long run times, which could be impractical due to extensive computational requirements.

A particular discrete model is the discrete fracture network (DFN) method. A DFN explicitly models fractures as discontinuous features defined by random variables with inferred probability distributions (Xu \& Dowd 2010). Consequently, a DFN can incorporate the geometry of the joints to represent the heterogeneous nature of the rock mass, which is not explicitly incorporated in other approaches. The major problem of this method is that fracture characterisation cannot be accurately defined before set up of the problem or even after solving the problem. In other words, the fracture system geometry is uncertain, except for some major discontinuities that can be deterministically defined (Jing \& Stephansson 2007). A DFN model has been used to qualitatively interpret the natural fragmentation of the rock mass as a function of persistence and spacing, but further research needs to be done, particularly to normalise the block volume to a block cave mine-scale (Elmo et al. 2014).

\section{Identification and representation of critical factors affecting caveability using DEM}

Caveability is defined as the ability of the rock mass to unravel naturally after undercutting. The caved material is recovered through drawpoints, which needs to be fragmented enough to flow freely. The size of these fragments of rock tends to decrease due to crushing, abrasion or bulk fracture. Rock flow has been simulated using 3DEC by prior shrinkage of the blocks, which is a solution to better represent the problem (Taghavi \& Pierce 2011). However, limited studies have been done using discrete element codes attempting to represent caveability, and therefore, considerations or limitations have not been clearly established. 3DEC, a DEM code, combined with DFN have the advantage that it can incorporate joints and reproduce 
crack initiation, coalescence and propagation, which directly impact on the macroscopic behaviour of the rock mass. The rock mass response is obtained as a result of the simulation and is not previously defined as input data, which means the rock mass response results from combining both intact rock and joint behaviour. The understanding of how critical factors affect caveability and their influence on caving mechanisms is necessary to better-predict the rock mass behaviour during caving. This understanding can be obtained as a result of numerical modelling using 3DEC. Different rock masses can be modelled in order to test their responses and compare them.

A general approach to understanding caveability needs to consider at least that the rock mass characteristics can impact caveability as much as the mine plan and the manner in which ore is drawn (Kendorski 1978). Therefore, a reliable caveability prediction tool needs to include the geology where the mine is located, the mine design developed to cave the deposit, and the strategy followed to extract the caved material in the operation to be reliable. The following section qualitatively describes each of these components and how they can be incorporated into a discrete element model to better understand caveability.

\subsection{Geological factors}

Geological factors are considered to be those that describe the rock mass and its properties as well as those that cannot be completely controlled during mine design or operation, such as in situ stresses and water. These factors cannot be explicitly quantified because the number of developments and exposures in the rock mass is limited. As a consequence, the quality of the quantification of these factors can be affected by human subjectivity and simplistic assumptions, and only valid to represent the location where the data is collected. Geological factors are incorporated in empirical methods for caveability prediction as a measure of the rock mass quality. These factors and their importance to caveability are described as follows.

\subsubsection{Rock mass structure}

The rock mass structure refers to the destruction of the intactness of the rock mass by discontinuities; consequently, it can show the location of weaker strength. The rock mass is characterised by discontinuities of different sizes and scale. Joints are particularly essential for caveability since a combination of favourable sets in a low lateral confinement environment can ease caving (Brown \& Trollope 1970). Joints also can influence caving in high confinement cases because they represent potential failure planes. At larger scales, faults impact can be more severe on cave propagation because they have the potential to redistribute stresses allowing more freedom for rock mass movement than the vertical if they are favourably located within the cave (Kendorski 1978). In general, the rock mass can be strengthened if the principal stress direction is perpendicular to a major discontinuity set (Jakubec \& Laubscher 2000).

Discontinuities can form blocks of intact rock, and the average block size can be used as an indicator to quantify the rock mass structure. Bigger sizes can subsequently progress to large blocks causing difficulties in material handling, while smaller sizes can progress to fine material that can stop the muck flow. The location of different block geometries can be used to define their stability by using the key block theory (Goodman \& Shi 1985). Even when most of the blocks could not be removed from the rock mass, this technique considers the measurement of the likelihood of caving propagation under low confining stresses based on the number of removable blocks (Karzulovic 1999).

Three geometrical characteristics of discontinuities that can critically impact caveability are their orientation, spacing and persistence. The orientation of sub-vertical dipping joints can determine the direction in which caving propagates and flat dipping joints can help the rock mass to cave (Laubscher 2000; Vyazmensky 2008). The absence of weakness planes favourably oriented may lead to the development of a stable arch (Mawdesley 2002). The spacing of discontinuities also plays an important role in caveability since one fracture is not sufficient to initiate caving. The best case for caving is a rock mass with several sets of intense fracturing having low shear resistance (Kendorski 1978). Finally, the persistence defines the discontinuous behaviour of the rock mass for a given scale. A rock mass with non-persistent discontinuities 
will form only a few blocks and a high number of intact rock bridges, which will increase the rock strength (Kim et al. 2007) and inhibit caveability.

Parameters described previously are included in classification systems as presented in Table 1 . Both $Q$ and MRMR assign high ratings to rock structure compared to other rock mass characteristics, such as strength. Q-system considers the quotient RQD/Jn as a measure of the relative block size, where RQD is the rock quality designation (Deere 1963) and Jn represents the joint set number. The maximum value of RQD/Jn is 200 , when the rock mass has a few joints, but this interpretation contradicts the definition of RQD/Jn which is defined as block size. On the other hand, MRMR considers the spacing of fully persistent and continuous joints, which is only applicable to a limited number of rock masses (Laubscher 1990). Another limitation of these approaches is that they only represent the scale and purpose of the problem for which they were created, which means that a set of discontinuities could be persistent and widely spaced at a tunnel-scale but not necessarily at a mine-scale. Also, factors considered critical for tunnel stability are not necessarily critical for caveability prediction. Consequently, these classification systems do not properly represent the rock mass structure affecting caveability.

Table 1 Ratings related to rock mass structure in classification systems used for caveability prediction

\begin{tabular}{ll}
\hline Classification system & Ratings related to rock mass structure \\
\hline Barton's Q (1974) & $\begin{array}{l}\text { Extremes values for the quotient RQD/Jn are } 0.5 \text { when RQD is between } 0 \\
\text { and } 25 \text { and the rock is crushed, and } 200 \text { when RQD is between } 90 \text { and } 100 \\
\text { and the rock mass has few joints. }\end{array}$ \\
Laubscher's MRMR (1990) & $\begin{array}{l}\text { Extremes values for rating (RQD) + rating (joint spacing) (or rating (FF/m)) } \\
\text { are } 0 \text { when the rock mass has three sets of joints and more than } 40 \text { joints } \\
\text { per metre, and } 40 \text { when the rock mass has three sets of joints and less than } \\
0.2 \text { joints per metre (spacing }>5 \mathrm{~m}) .\end{array}$ \\
\hline
\end{tabular}

An investigation to quantify the influence of the rock mass structure on caveability can be conducted using 3DEC. For this purpose, the interaction of blocks of various sizes and shapes can be considered, which is described by discontinuities following different distributions of orientation, spacing, persistence, and which are under the influence of a given field stress. In 3DEC, blocks can be formed when a DFN is incorporated. Blocks in 3DEC can be zoned, or in other words, they can be divided into tetrahedral or quadrilateral elements, which may follow a given constitutive law. In the case of non-persistent joints, they need to be incorporated into the model. The defined zones can be converted into blocks, and their contacts characterised by given joint properties. Unfortunately, there are not enough computational resources available to date to run a detailed model representing realistic dimensions of block caves, and therefore, the scale of the problem will limit results obtained from a 3DEC model. Even considering this limitation, the use of blocks of different shapes and sizes can help improve the understanding of caving mechanisms which are controlled by the interaction of blocks.

Figure 2 presents different block geometries that can be incorporated in 3DEC. Figures 2(a) and 2(b) are created by dividing the original block into tetrahedral blocks and cubes respectively, which represent blocks with same size and shape within a configuration. Figure 2(c) is created based on a DFN, where blocks have different shape and size and finally, Figure 2(d) represents an initial block cut by a DFN and subsequently subdivided into smaller tetrahedral blocks of various sizes. The last configuration can allow representing persistent joints by a DFN and non-persistent joints by the sides of tetrahedral blocks. 


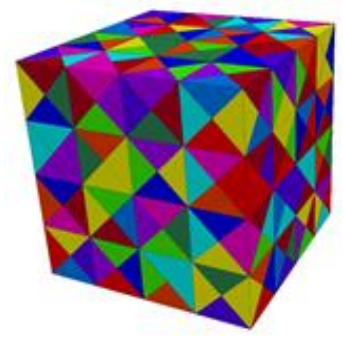

(a)

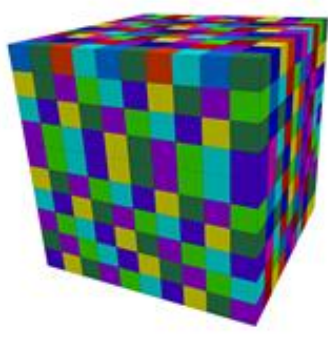

(b)

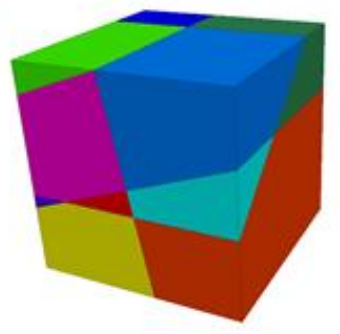

(c)

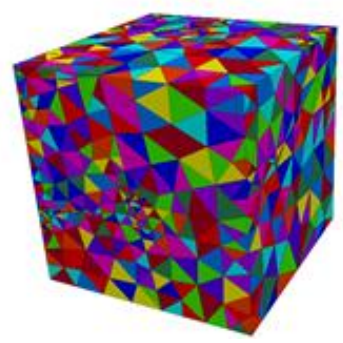

(d)

Figure 2 Different block geometries that can be modelled in 3DEC

\subsubsection{Mechanical properties of the rock mass}

The main advantage of ideal caving methods is that the rock mass fails under its own weight, for which horizontal stresses can contribute to assist or delay the propagation (Morrison 1976). Therefore, the property of interest is the rock mass strength because caving initiates only if induced stresses overcome its value. This is critical because caving rate has to be enough to ensure continuous production. Another important mechanical property is deformability, which is expected to be reduced during caving as the rock mass increases in volume due to the separation and rotation of blocks (Sainsbury 2010).

The effect of discontinuities has to be accounted for in the global rock mass strength because they can slip and make the rock mass fail. A block of rock defined by discontinuities can fall if it is suitably oriented with respect to gravity loading to satisfy the criterion of frictional slip conditions. The shear strength can be destroyed in two steps, first, the failure of intact bridges, and then, the shear on the joints at larger strains. Three strength components can define the shear strength of joints: degradation of cohesion, mobilisation of friction, and mobilisation of dilation (Barton 2014). Rock mass dilation is particularly critical to correctly predict the bulking behaviour of the rock mass during cave propagation (Sainsbury 2010).

The tensile strength of discontinuities is also critical, but not usually considered. The tensile strength of open joints in jointed rock masses is often neglected because it is almost zero. However, rock masses including filled and healed joints or foliations, are affected by their tensile strength which plays a major role in caveability and fragmentation, and their effect cannot be neglected. In veined rock masses, the failure can be characterised by either shear through vein infill or tension in the vein-rock interface. Unfortunately, cemented joints are often inevitably spuriously classified as open joints or sometimes just ignored (Brzovic 2010; Jakubec \& Laubscher 2000).

Parameters described previously are included in classification systems as presented in Table 2. Both $Q$ and MRMR consider mechanical properties as critical for rock mass quality, but the Q-system only incorporates the quotient $\mathrm{Jr} / \mathrm{Ja}$ indicating the inter-block shear strength, where Jr represents the joint roughness number and Ja the joint alteration number. On the other hand, MRMR also includes a rating for intact rock strength but not shear or tensile strength. Combining intact rock strength (IRS) and joint conditions ratings, MRMR considers the mechanical properties of the rock mass as the most critical parameter affecting caveability. 
Table 2 Ratings related to mechanical properties in classification systems used for caveability prediction

\begin{tabular}{ll}
\hline Classification system & Ratings related to mechanical properties \\
\hline Barton's Q (1974) & $\begin{array}{l}\text { Extremes values for the quotient Jr/Ja are } 0.025 \text { when joints are } \\
\text { slickensided, planar and contain thick zones of clay, and } 5.33 \text { when joints } \\
\text { are discontinuous and tightly healed. }\end{array}$ \\
Laubscher's MRMR (1990) & $\begin{array}{l}\text { Extremes values for rating(IRS) + rating (joint condition) are 0 when IRS is } \\
\text { between } 1 \text { and 4 MPa and joints are straight, polished and filled, and } 60 \\
\text { when the IRS }>185 \mathrm{MPa} \text { and joints are multi-wavy directional, irregular, } \\
\text { and there is no filling. }\end{array}$ \\
\hline
\end{tabular}

Mechanical properties describing the rock mass can be incorporated in 3DEC to adequately describe both blocks and joints, which later can be compared with induced stresses to define failure modes and mechanisms. Particularly interesting is the incorporation of open joints or veins, which are differentiated by their shear and normal strength.

\subsubsection{Field stress}

The induced field is mainly influenced by the in situ stresses, the initial topography, excavations developed in the rock mass, joints and major structures (Laubscher 2000). The magnitude and orientation of the in situ stresses are particularly critical because they dictate the nature of the stress redistribution around the undercut excavation. However, even when the stability of the excavation is essential for the operation's success, the estimation of stresses is still subjected to measurement errors that remain at unacceptable levels in other engineering disciplines (Hoek 1994). At higher depths, there is a tendency for rock masses to be stronger as a result of less intense fractures, and be influenced by a reduced effect of weathering and stress relief opening of fractures (Barton 2006; Kendorski 1978).

The influence of the stress field is included in $Q$ and MRMR classification systems as presented in Table 3. The influence of the horizontal stress field on the stability of the rock mass is reflected in higher ratings because the rock mass will be restricted to the cave even under favourable structural circumstances if stresses lock rock blocks together and cancel the tensional forces (Kendorski 1978). On the contrary, the most favourable condition for caving, and less favourable condition for instability, is a structurally dominant rock mass characterised by reduced confinement. In the Q-system, instability due to a rockburst is considered to be more critical compared to instability due to low confinement because its emphasis is on tunnel stability. However, the stress reduction factor (SRF) is not considered as a factor in the stability number $\mathrm{N}$, since it was replaced by Factor $\mathrm{A}$ to account for the effect of stress acting on the stope surface. A low Factor A implies stress-induced fracturing in the rock mass to reduce its quality, which is critical to consider in open stope stability for the management of dilution.

Table 3 Ratings related to stress field in classification systems used for caveability prediction

\begin{tabular}{ll}
\hline Classification system & Ratings related to mechanical properties \\
\hline Barton's Q (1974) & $\begin{array}{l}\text { The stress field is accounted for by the SRF, which reduces the final value of } \\
\text { Q. Extremes values for the SRF are } 0.5 \text { when structures are tight due to high } \\
\text { stress which increases the rock mass quality, and } 20 \text { when stresses are high } \\
\text { enough to cause a rockburst which reduces the rock mass quality. }\end{array}$ \\
Laubscher's MRMR (1990) & $\begin{array}{l}\text { Extremes values for the adjustment for mining-induced stresses are } 60 \% \\
\text { when a large difference between maximum and minimum stresses result in } \\
\text { shearing along the joints, and } 120 \% \text { when a compressive stress at a large } \\
\text { angle to joints increases the stability of the rock mass and inhibits caving. }\end{array}$ \\
\hline
\end{tabular}


The main advantage of discontinuum methods is that they can incorporate discontinuities, which play a critical role in the distribution of stresses after excavating the rock mass because of their low shear stiffness and strength (Brown 2004). The in situ stress field is incorporated into a 3DEC model as boundary conditions when the model is initially created. The redistribution of stresses can be continuously checked when caved material is extracted in the base of the block.

\subsubsection{Water}

Water flows through the aperture of multiple fractures only when they are connected; in other words, the rock mass structure needs to allow intersections. Water in the potential cave zone can assist caving by reducing joint friction, increasing pore water pressure, and reducing the rock mass strength when rocks are prone to extensive weathering (Laubscher 2000). The rate of water flow through the column will vary depending on the height of the column, the percentage of the area under active draw and the fragmentation of the cave material having an impact on the caving rate (Laubscher 2000). Large quantities of water flowing out of drawpoints affect the working conditions and increase the possibility of mud rushes.

The influence of water is included in classification systems as presented in Table 4. Comparing $Q$ and MRMR systems, the Q-system reduces more drastically the rock mass quality than MRMR under highly unfavourable water conditions. However, the water reduction factor is not considered as a factor in the stability number $\mathrm{N}$, which is used for caveability prediction in the extended Mathews stability graph.

Table 4 Ratings related to water in classification systems used for caveability prediction

\begin{tabular}{ll}
\hline Classification system & Ratings related to mechanical properties \\
\hline Barton's Q (1974) & $\begin{array}{l}\text { A dry condition does not change the final value of Q, and the most extreme } \\
\text { situation reduces its value to its 5\% under exceptionally high inflow. }\end{array}$ \\
Laubscher's MRMR (1990) & $\begin{array}{l}\text { Depending on the joint condition, the final rating can be reduced to a } \\
\text { maximum of } 10 \text { points (10\%) under high-pressure conditions of water. }\end{array}$ \\
\hline
\end{tabular}

\subsection{Mining factors}

Block caving is a mining method used in massive orebodies characterised by a large and regular footprint, which can be divided into blocks. A variant of block caving is panel caving, where the undercut area is incorporated in a continuous pattern of panels giving more flexibility to the extraction. Mining factors describing both caving methods that potentially impact caveability are the undercut level location and the block size that dictate the undercut size of hydraulic radius.

The elevation and orientation of the undercut level depend on the rock mass, stress state, and mining costs. There is now a tendency to locate extraction levels deeper, adjacent to old exploited caves, or beneath deep open pits or previously exploited caves, which are cases related to higher stresses. The preferred direction of undercut advance should be the one that reduces stresses in the cave back as mining progresses, and it should be chosen as a combination of the shape of the orebody and the direction of the major principal stress (Diering \& Laubscher 1987).

The size of the block to be caved refers to both the plan area and the height of the extracted column. First, the accumulated plan area has to be large enough to enable the initiation of caving through the whole block height, which means it is critical for caveability. However, the area is not sufficient by itself and the shape of the undercut should also be considered. For instance, narrow rectangular undercuts are more prone to form stable arches than equidimensional undercuts with the same plan area (Laubscher 2000). Second, the height of the extracted column depends on the orebody geometry and value, cost of extraction, economic life of extraction horizon and potential production per drawpoint (Laubscher 1993). Block heights have progressed over time from 30 to $50 \mathrm{~m}$ in early block caving mines to even up to $600 \mathrm{~m}$ in recent operations (Bullock \& Hustrulid 2001; Moss et al. 2006). A higher draw column will have greater exposure of the material 
to comminution, but it will mean much less control over the rock mass. In fact, only a few cases have succeeded with block heights over 200 m in strong orebodies (Kendorski 1978; Mawdesley 2002).

The only mining factor incorporated in traditional empirical methods for caveability prediction is the accumulated plan area. Both, the Laubscher's caveability chart and the extended Mathews stability graph, have as the only common element the measure of the excavation geometry, which is defined by the hydraulic radius (HR) or shape factor (SF). This value is derived by dividing the area of the excavation surface by its perimeter. This plan measure has been useful to predict cave initiation considering a flat back shape of the undercut; however, this value does not account for the arched profile formed during cave propagation, which usually results in cave propagation stalling.

\subsection{Operational factors}

An operational factor can be controlled, contrary to geological and mining factors. Operational factors are the only factors that can be changed to improve caveability once the mine has been developed. The draw strategy can particularly minimise high caving rates caused by concentrated weak and highly fractured zones, minimise dilution and horizontal migration of ore, control fragmentation, direct water within the cave, and prevent conditions leading to stability problems such as overloading of pillars, formation of stable arches, formation of air gaps and mud rushes (Kendorski 1978; Laubscher 2000).

Geological factors will influence the rock mass behaviour under draw, particularly the block size distribution and their shape. In case the rock mass is weak, it may fully fragment most of the column during undercutting, while a strong rock mass may stall sporadically. These geological parameters need to be considered in the draw strategy since draw rate of the caved material must be related to the natural caving rate. The caving rate defines the maximum height that could be reached by natural vertical propagation for a certain undercut area, which is not necessarily the block height defined as part of the mine design (Flores 2004). The minimum draw rate has to be enough to make the rock mass fail; however, production is based on economic factors that may result in a higher draw than caving rate with adverse consequences. If the draw rate exceeds caving rate, stresses build up in the back prior to the intermittent caving that potentially could develop a self-supporting arc (Laubscher 2000). One alternative to reducing the rate of caving is controlling the draw, as the cave can only propagate when there is space into which the rock can move, while an alternative to increasing the rate of caving is drawing more rapidly (Laubscher 2000).

The optimal strategy to control the draw plan is to ensure uniform draw, because it generates little relative movement between blocks compared to zones in interactive draw (Laubscher 2000). In any case, the production scheduling must be flexible to address difficulties including either loss of draw control or underdraw. Loss of draw control can be caused by operators favouring draw from particular drawpoints, while underdraw can be caused by hang-ups or blocked drawpoints (Kendorski 1978).

\section{$4 \quad$ Conclusions}

This paper highlighted the relevance of identifying critical parameters affecting caveability, which should be included as a basis for a better caveability prediction guide, as well as discussing the main limitations of their representation in empirical tools for predicting caveability. Caveability prediction approaches have been improved by many authors but they still have flaws. Firstly, the real impact of the different parameters affecting caveability has not been adequately quantified. The quantification of the geology in empirical methods usually follows standard recommendations, which have not proved to represent the caveability problem, while numerical models have only been limited to represent specific conditions in a particular mine or general conditions representing only a few parameters. Secondly, both empirical methods and numerical modelling consider input data extrapolated from laboratory data, which do not necessarily incorporate the failure mechanisms at the scale of the problem. Even though parameters describing discontinuities are impacted by scale effect, they are usually classified as small or large-scale properties without indicating that large-scale represents a mine-scale problem. 
As presented before, critical parameters affecting caveability can be incorporated into a 3DEC model in order to test the response of rock masses characterised by different properties. These results can be compared to caving mechanisms registered in documented caving cases with the purpose of creating new guidelines to design caving mines. Because of this, further research is proposed based on discontinuum modelling in 3DEC aiming to better-describe the behaviour of the rock mass under caving conditions based on the influence of each critical parameter affecting it.

\section{Acknowledgement}

The authors gratefully acknowledge UNSW Sydney for the Tuition Fee Scholarship and Itasca for their help in the development of this project through their Itasca Education Partnership (IEP) program.

\section{References}

Barton, N 2006, 'Relationships between rock quality, depth and seismic velocity', Rock Quality, Seismic Velocity, Attenuation and Anisotropy, Taylor \& Francis Group, London.

Barton, N 2014, 'Shear strength of rock, rock joints and rock masses - problems and some solutions', in LR Alejano, A Perucho, C Olalla \& R Jimenez (eds), Proceedings of the 2014 ISRM European Rock Mechanics Symposium, Taylor \& Francis Group, Vigo, pp. 3-16.

Barton, N, Lien, R \& Lunde, J 1974, 'Engineering classification of rock masses for the design of tunnel support', Rock Mechanics, vol. 6 , no. 4, pp. $189-236$.

Bieniawski, ZT 1973, 'Engineering classification of jointed rock masses', Transactions of the South African Institution of Civil Engineers, vol. 15, no. 12, pp. 335-344.

Brown, ET 2002, Block Caving Geomechanics, Julius Kruttschnitt Mineral Research Centre, Brisbane.

Brown, ET 2004, 'The mechanics of discontinua: engineering in discontinuous rock masses', in G Farquhar, P Kelsey, J Marsh \& D Fellows (eds), Proceedings of the Ninth Australia-New Zealand Conference on Geomechanics, The University of Auckland, Auckland, pp. 51-72.

Brown, ET \& Trollope, DH 1970, 'Strength of a model of jointed rock', Journal of Soil Mechanics and Foundations Division, vol. 96, no. 2, pp. 685-704.

Brzovic, A 2010, Characterisation of Primary Copper Ore for Block Caving at the El Teniente Mine, Chile, PhD thesis, Curtin University of Technology, Bentley.

Bullock, RL \& Hustrulid, WA 2001, 'Planning the underground mine on the basis of mining method', in WA Hustrulid \& RL Bullock (eds), Underground Mining Methods: Engineering Fundamentals and International Case Studies, Society for Mining, Metallurgy and Exploration, Englewood.

Cai, M \& Horii, H 1993, 'A constitutive model and FEM analysis of jointed rock masses', International Journal of Rock Mechanics and Mining Sciences \& Geomechanics Abstracts, vol. 30, no. 4, pp. 351-359.

Cundall, PA \& Strack, ODL 1979, 'A discrete numerical model for granular assemblies', Géotechnique, vol. 29, no. 1, pp. 47-65.

De Nicola, R \& Fishwick, M 2000, 'An underground airblast-CODELCO Chile-Division Salvador', Proceedings of the Third International Conference and Exhibition on Mass Mining, The Australasian Institute of Mining and Metallurgy, Melbourne, pp. $279-288$.

Deere, DU 1963, 'Technical description of rock cores for engineering purposes', Rock Mechanics and Engineering Geology, vol. 1, no. 1 , pp. 16-22.

Diering, J \& Laubscher, DH 1987, 'Practical approach to the numerical stress analysis of mass mining', Transactions of the Institution of Mining and Metallurgy, Section A: Mining industry, vol. 96, pp. 179-188.

Elmo, D, Rogers, S, Stead, D \& Eberhardt, E 2014, 'Discrete Fracture Network approach to characterise rock mass fragmentation and implications for geomechanical upscaling', Mining Technology, vol. 123, no. 3, pp. 149-161.

Elmo, D, Vyazmensky, A, Stead, D \& Rogers, S 2012, 'Applications of a finite discrete element approach to model block cave mining', in L Ribeiro e Sousa, E Vargas Jr., M de Matos Fernandes \& R Azevedo (eds), Innovative Numerical Modelling in Geomechanics, Taylor \& Francis Group, London.

Flores, GE 2004, Rock Mass Response to the Transition From Open Pit to Underground Cave Mining, PhD thesis, University of Queensland, Brisbane.

Garza-Cruz, T \& Pierce, ME 2016, 'Impact of rock mass strength variability on caving', Proceedings of the Seventh International Conference and Exhibition on Mass Mining, The Australasian Institute of Mining and Metallurgy, Melbourne, pp. 359-368.

Goodman, RE \& Shi, GH 1985, Block theory and its application to rock engineering, Prentice-Hall, New Jersey.

Hoek, E 1994, 'The challenge of input data for rock engineering', letter to the editor, ISRM News Journal, vol. 2, no. 2, pp. 23-24.

Itasca Consulting Group, Inc. 2014, PFC3D - Particle Flow Code in 3 Dimensions, version 5.0, Itasca Consulting Group, Inc., Minneapolis, viewed 27 June 2017, http://www.itascacg.com/software/pfc

Itasca Consulting Group, Inc. 2016, 3DEC - 3 Dimensional Distinct Element Code, version 5.2, Itasca Consulting Group, Inc., Minneapolis, viewed 27 June 2017, http://www.itascacg.com/software/3dec 
Jakubec, J \& Laubscher, DH 2000, 'The MRMR rock mass rating classification system in mining practice', Proceedings of the Third International Conference and Exhibition on Mass Mining, The Australasian Institute of Mining and Metallurgy, Melbourne, pp. 413-421.

Jing, L 1998, 'Formulation of discontinuous deformation analysis (DDA) - an implicit discrete element model for block systems', Engineering Geology, vol. 49, no. 3, pp. 371-381.

Jing, L 2003, 'A review of techniques, advances and outstanding issues in numerical modelling for rock mechanics and rock engineering', International Journal of Rock Mechanics and Mining Sciences, vol. 40, no. 3, pp. 283-353.

Jing, L \& Hudson, JA 2002, 'Numerical methods in rock mechanics', International Journal of Rock Mechanics and Mining Sciences, vol. 39, no. 4, pp. 409-427.

Jing, L \& Stephansson, O 2007, Fundamentals of discrete element methods for rock engineering, Elsevier, Netherlands.

Karzulovic, A 1999, 'Evaluación de la Propagación del Caving mediante Teoría de Bloques', technical report to División El Teniente, Codelco, Rancagua.

Kendorski, FS 1978, 'The cavability of ore deposits', Mining Engineering, vol. 30, no. 6, pp. 628-631.

Kim, BH, Cai, M, Kaiser, PK \& Yang, HS 2007, 'Rock mass strength with non-persistent joints', in E Eberhardt, D Stead \& T Morrison (eds), Proceedings of the First Canada-U.S. Rock Mechanics Symposium, Taylor \& Francis Group, London, pp. 241-248.

King, RU 1945, 'A study of geologic structure at Climax in relation to mining and block caving', Transactions of the American Institute of Mining and Metallurgical Engineers, vol. 163, pp. 145-155.

Laubscher, DH 1990, 'A geomechanics classification system for the rating of rock mass in mine design', Journal of the South African Institute of Mining and Metallurgy, vol. 90, no. 10, pp. 257-273.

Laubscher, DH 1993, 'Planning mass mining operations', in JA Hudson (ed) Comprehensive Rock Engineering: Principles, Practice \& Projects, Pergamon Press, Oxford.

Laubscher, DH 2000, A Practical Manual on Block Caving, Julius Kruttschnitt Mineral Research Centre, Brisbane, Queensland.

Laubscher, DH \& Jakubec, J 2001, 'The MRMR rock mass rating classification for jointed rock masses', in WA Hustrulid \& RL Bullock (eds), Underground Mining Methods: Engineering Fundamentals and International Case Studies, Society for Mining, Metallurgy, and Exploration, Englewood.

Laubscher, DH \& Taylor, HW 1976, 'The importance of geomechanics classification of jointed rock masses in mining operations', in ZT Bieniawski (ed), Proceedings of the Symposium on Exploration for Rock Engineering, A.A. Balkema, Rotterdam, pp. 119-128.

Lisjak, A, Tatone, BS, Mahabadi, OK \& Grasselli, G 2012, 'Block caving modelling using the Y-Geo hybrid finite-discrete element code', Proceedings of the Sixth International Conference and Exhibition on Mass Mining, Canadian Institute of Mining, Metallurgy and Petroleum, Westmount.

Lorig, L, Board, MP, Potyondy, D \& Coetzee, MJ 1995, 'Numerical modeling of caving using continuum and micro-mechanical models', in HS Mitri (ed.), Proceedings of the Third Canadian Conference on Computer Applications in the Mineral Industry, McGill University, Montreal, pp. 416-425.

Mathews, KE, Hoek, E, Wyllie, DC \& Stewart, SBV 1981, 'Prediction of stable excavations for mining at depth below $1000 \mathrm{~m}$ in hard rock', technical report to Canada Centre for Mining and Energy Technology, Ottawa.

Mawdesley, CA 2002, Predicting Rock Mass Cavability in Block Caving Mines, PhD thesis, University of Queensland.

McMahon, BK \& Kendrick, RF 1969, 'Predicting the block caving behavior of orebodies', preprint 69-AU-51, Society of Mining Engineers of The American Institute of Mining, Metallurgical, and Petroleum Engineers, New York.

Mohammad Khani, M 2016, 'The application of rock engineering systems to block caving to identify the effective parameters', Proceedings of the Seventh International Conference and Exhibition on Mass Mining, The Australasian Institute of Mining and Metallurgy, Merlbourne, pp. 853-859.

Morrison, RGK 1976, A Philosophy of Ground Control: A Bridge Between Theory and Practice, McGill University, Montreal.

Moss, A, Diachenko, S \& Townsend, P 2006, 'Interaction between the block cave and the pit slopes at Palabora mine', Journal of the South African Institute of Mining and Metallurgy, vol. 106, no. 7, p. 479.

Obert, L, Munson, R \& Rich, C 1976, 'Caving properties of the Climax orebody', Transactions of the American Institute of Mining and Metallurgical Engineers, vol. 260, pp. 129-133.

Potvin, Y 1988, Empirical Open Stope Design in Canada, PhD thesis, University of British Columbia, Vancouver.

Rafiee, R, Ataei, M \& Khalokakaie, R 2015, 'A new cavability index in block caving mines using fuzzy rock engineering system', International Journal of Rock Mechanics and Mining Sciences, vol. 77, pp. 68-76.

Ross, I \& van As, A 2005, 'Northparkes Mines - design, sudden failure, air-blast and hazard management at the E26 block cave', Proceedings of the Ninth Underground Operators' Conference, The Australasian Institute of Mining and Metallurgy, Melbourne, pp. 7-18.

Sainsbury, BL 2010, 'Sensitivities in the numerical assessment of cave propagation', in Y Potvin (ed.), Proceedings of the Second International Symposium on Block and Sublevel Caving, Australian Centre for Geomechanics, Perth, pp. 523-535.

Sainsbury, BL 2012, A Model for Cave Propagation and Subsidence Assessment in Jointed Rock Masses, PhD thesis, The University of New South Wales, Kensington.

Shi, GH \& Goodman, RE 1988, 'Discontinuous deformation analysis - a new method for computing stress, strain and sliding of block systems', in PA Cundall, RL Sterling \& AM Starfield (eds), Proceedings of the 29th U.S. Symposium on Rock Mechanics, American Rock Mechanics Association, Alexandria, pp. 381-393.

Starfield, AM \& Cundall, PA 1988, 'Towards a methodology for rock mechanics modelling', International Journal of Rock Mechanics and Mining Sciences \& Geomechanics Abstracts, vol. 25, no. 3, pp. 99-106. 
Stewart, PC \& Trueman, R 2001, 'The Extended Mathews Stability Graph: Quantifying case history requirements and site-specific effects', in S Poirier (ed), Proceedings of the International Symposium on Mining Techniques of Narrow-Vein Deposits, Canadian Institute of Mining, Val-d'Or, pp. 85-92.

Stewart, SBV \& Forsyth, WW 1995, 'The Mathew's method for open stope design', CIM Bulletin, vol. 88, no. 992, pp. 45-53.

Suorineni, FT, Hebblewhite, B \& Saydam, S 2014, 'Geomechanics challenges of contemporary deep mining: A suggested model for increasing future mining safety and productivity', Journal of The Southern African Institute of Mining and Metallurgy, vol. 114, pp. 1023-1032.

Suorineni, FT, Kaiser, PK \& Tannant, DD 2001, 'Likelihood statistic for interpretation of the stability graph for open stope design', International Journal of Rock Mechanics and Mining Sciences, vol. 38, no. 5, pp. 735-744.

Taghavi, R \& Pierce, ME 2011, 'Modeling flow of fragmented rock with 3DEC: A polyhedral DEM approach', in DP Sainsbury, R Hart, C Detournay \& M Nelson (eds), Proceedings of the Second International FLAC/DEM Symposium, Itasca Consulting Group, Inc., Minneapolis, paper 14-03.

Vera, SG 1981, 'Caving at Climax', in DR Stewart (ed.), Design and Operation of Caving and Sublevel Stoping Mines, Society of Mining Engineers, New York, 843 p.

Vyazmensky, A 2008, 'Numerical modelling of surface subsidence associated with block cave mining using a finite element/discrete element approach', PhD thesis, Simon Fraser University, Burnaby.

Vyazmensky, A, Elmo, D, Stead, D \& Rance, J 2007, 'Combined finite-discrete element modelling of surface subsidence associated with block caving mining', in E Eberhardt, D Stead \& T Morrison (eds), Proceedings of the First Canada-U.S. Rock Mechanics Symposium, Taylor \& Francis Group, London, pp. 467-475.

Xu, C \& Dowd, P 2010, 'A new computer code for discrete fracture network modelling', Computers \& Geosciences, vol. 36, no. 3, pp. 292-301. 
